\title{
Marketing Services to Promote Art \& Handicraft Practices Adopted by the Self Help Groups of Shimla District, Himachal Pradesh.
}

\author{
Devender Sharma
}

\begin{abstract}
Marketing services provided by government agencies to promote art and handicraft. The key objectives of the study were, to study various marketing services provided by government agencies to promote art and handicraft, the awareness level of self-help groups, perception of the self-help groups towards marketing schemes used by government agencies to promote art and handicraft. A structured questionnaire was prepared for the present study. It was found that skills training on handicraft and cluster development were the schemes useful for the promotion of art and handicraft.
\end{abstract}

Keywords: Art \& Handicraft, Cluster Marketing Services, Promotion.

\section{INTRODUCTION}

Handicraft, precisely and more usually refers to artisanal work or handmade items fulfil daily needs and creative things are made purely by hands or by using common tools and methods. It is an old and artisanal sector of craft and refers to a wide range of creativity and form activities that are linked to making useful final products with hands and creative skills, it includes work with cotton, raw material, wood, plants, stones etc. Art and Handicraft was one of the important elements of the formation of Indian culture in the 19th and 20th centuries, as social formation started promoting village-based handicrafts for the cultural and economic growth of India. Mahatma Gandhi charka refers to this profound idea and became a potential method for the had successfully capitalized Indian cultural arts and crafts. Art and Handicraft are always being a significant part of the life and culture of Himachal Pradesh. Art and Handicraft products are usually referring to more traditional and cultural related work, done by self-help groups in rural and urban areas. People create products in day to day life for their income. Arts and crafts of Himachal Pradesh are always have been an important part of people's lives.

Himachal Pradesh is one of those states which has a rich culture and we can see it in handicrafts products People still uses old techniques for creating their arts and handicrafts. It is the main industry of Art and Handicraft and refers to a huge option of artisanal and creative activities that include making things with hands and tools, it includes moldable and raw

Revised Manuscript Received on April 15, 2020.

* Correspondence Author

Devender Sharma*, Assistant Professor, Green Hills Engineering college Solan Himachal Pradesh.

(c) The Authors. Published by Blue Eyes Intelligence Engineering and Sciences Publication (BEIESP). This is an open access article under the CC BY-NC-ND license (http://creativecommons.org/licenses/by-nc-nd/4.0/) fight for India's independence. The long-time of socialism

material, wood, stones, etc. Mainly art and handicraft refer to old Methods of producing final products.

\section{LITERATURE REVIEW}

(Effat Yasmin, 2013) Studied the handicraft process in Kashmir Valley which is culturally sound. Kashmir has its own rich culture which we can see in handicrafts. These products are in huge demand nationally and internationally. There is potential growth in future. (Shreya Jadhav, 2013). Studied the Art and handicraft sector. The study found that the availability of low-cost labour in the locality, creative artisan work in the producing of things with the potential growth in the future. (Ernst Young, 2012) studied the art and handicraft sector in India which include a huge number of workers and artist from rural and urban areas. The rural SHG groups contributing $80 \%$ of the units produced where the urban groups contributing rest. In these types of groups, there are lots of women \& people economically unsound. The main advantage of this sector availability of low-cost labour in the country, cheaper resources, less investment and cultural creativity. (Handicraft Economics \& effect Survey, 2011) The economic survey found that the most significant reason or the single most effective cause behind all of the problems of the self-help groups was an underestimation. This sector is still underestimated but its economic potential making a significant contribution to the economy. (Centre for Management Development, (2004) The study titled "Study on Handicrafts-Problems and prospects" conducted by the Trivandrum found that the Government marketing agencies for handicrafts are charging extra for the crafts supplied by the artisans to an extent of 50 to 60 per cent to cover the overheads of the agencies. This will lead to an increase in the Ultimate price of the crafts retarding sales and preventing the growth of the handicraft sector. (Indian Government, 2002). The study has been done on expenses on Handicrafts in India. The important purpose of the study to analyse the role of stakeholders in promoting handicrafts The sample size of 100 has been taken. Half of the responders believe that art and handicraft are significant in representing the region's culture. (Institute of Small Enterprises and Development (2001) studied Industrial Development of Kerala in which they find out that sickness and death of industrial groups and SHG is a major problem; bogus registration of groups are also a negative feature of SHG growth.

Published By:
Blue Eyes Intelligence Engineering \& Sciences Publication (C) Copyright: All rights reserved. 
The results show that since the late 1970s, a huge number groups have been registered and most of them are sick or dormant (The Times of India (2000) studied working process of SHG groups" and found that half per cent of groups other than weavers' SHG Groups are dormant in India. The main cause was lack of credit facilities, lack of managerial expertise, inappropriate promotional support and lack of training to create efficient workers.

\section{RESEARCH METHODS}

The research method is a scientific way to solve the study problem. It may be understood as the science of studying and art of implementation that how research is done smoothly. When we say about the methods, we not only say about research methods but also refers to the rationality behind the methods or technique and why we are not using others. Research process starts with conveying research problem, creating a hypothesis, design research, collection of information and finding interpretation and analysis of data to form a report.

Analysis Design: An analysis format found fit as the framework or plan for the analysis that direct as well as help the information gathering and analysis of data. The descriptive research design has opted for the following research study.

Population and research area: The current analysis has been done in two Blocks of Shimla Himachal Pradesh. The Self-Help Groups from both the Blocks have been taken as a research population.

Sampling technique: The sample is referring to the proportion of the population that is representing the whole sample size. The number of groups in a sample is called a sample unit. Convenience sampling technique has been used for gathering the data. It is (also named as grab or opportunity sampling) a type of non-probability sampling method where samples are selected because of their convenient approach and proximity to the study.

Sample size: The sample size of 20 Self-Help Groups has opted for the current study.

Information Gathering: Two types of information have been gathered for the current study.

Primary Data: The primary data is that data which is gathered for the first time. Primary data has been gathered through a closed-ended structured interview schedule. The questionnaire has been parted into two parts. Part ' $A$ ' was created to seek info. on the demographic variables such as name, age, gender, etc. Part ' $B$ ' created for general opinions and statements based on 5-point Likert scale to calculate the satisfaction and attitude of the self-help groups towards market services schemes.

Secondary Data: The earlier gathered data are those which have been gathered by someone else. gathered data has been taken from journals, magazines, research articles, newspaper, and books

Statistical Method: Further analysis methods have been used to observed the data collected for the current study.

Arithmetic Mean: The arithmetic mean has been used to analyses the opinion of the sample responders on a 5-point scale for different raw outputs. This method helps the observer to get the right inferences from the outputs gathered from the responders. The arithmetic mean has been evaluated by giving numerical values to the qualitative outputs. These values have been assigned for these qualitative outputs as one for strongly disagree, two for do not agree, three for nor agree neither disagree, four for agree and five for strongly agree.

$$
\begin{aligned}
& \mathrm{X}=\frac{\Sigma X}{N} \\
& \mathrm{X}=\text { Arithmetic Mean } \\
& \sum \mathrm{X}=\text { Sum of the values of the variables } \\
& \mathrm{N}=\text { Number of Observation }
\end{aligned}
$$

Standard Deviation: The standard deviation tool was found by Karl Pearson in 1823. The standard deviation measurements the absolute dispersion (or variability of distribution; the higher the value of dispersion or variability), the higher the standard deviation, the higher will be the magnitude of the deviation of the outputs from their mean. A small standard deviation means a high degree of uniformity of the observed frequencies as well as a mixture of the series; a huge standard deviation means just the opposite.

$$
\begin{aligned}
& \quad \text { Standard Deviation }=\sqrt{\frac{\sum \times 2}{N}} \\
& \begin{array}{c}
\mathbf{x}=(\boldsymbol{x}-\bar{x}) \\
\mathrm{N}=
\end{array} \\
& \text { Number of raw outputs }
\end{aligned}
$$

Total Weightage Score Method: Total Weightage Score Method is a tool in which we have to give different Weights according to their significance and multiply the outputs of the items (X) by the weights (W) as given. Then add all the outputs to get the total weights of all the variables and the one which gets the highest score will get the first place and the one which has the lowest score will get the lowest rank.

Chi-Square test: A $\mathrm{Chi}^{2}$ test is an analysis tool used to determine differences with different variables.

Formula:

$$
\begin{aligned}
& \mathrm{x}^{2}=\sum_{\text {Where, }} \frac{(\mathrm{O}-\mathrm{E})^{2}}{\mathrm{E}} \\
& \mathrm{O}=\text { the frequency observed, } \\
& \mathrm{E}=\text { the frequency expected, } \\
& \quad \sum=\text { the sum of. }
\end{aligned}
$$

For a contingency form that has $r$ rows and $c$ columns, the $\mathrm{Chi}^{2}$ test can be used as a test of independence. In a test of independence, the null and alternative hypothesis are: Ho: The two categorical variables are independent. Ha: The categorical variables are related.

\section{RESULTS AND DISSECTION}

This lesson deals with the output and scrutiny of the results. The results of the dissection have been discussed further.

\section{Part A: DEMOGRAPHIC REPRESENTATION OF THE RESPONDENTS DATA}

Table 4.1.1 Note of the respondents

\begin{tabular}{|l|c|}
\hline \multicolumn{1}{|c|}{ Blocks } & Self-Help Groups \\
\hline 2 & 20 \\
\hline Total 2 & 20 \\
\hline
\end{tabular}

The concerned study has exhibited a small proportion of self-Help Groups mainly female respondents. Since the male respondents were less interested and actively involved with the Art and Handicraft Activities. 
Table 4.1.2 Block of the respondents

\begin{tabular}{|c|c|}
\hline State & $\begin{array}{c}\text { Number of respondents } \\
\text { (\%age) }\end{array}$ \\
\hline Rampur & $10(50)$ \\
\hline Theog & $10(50)$ \\
\hline Total & $\mathbf{2 0 ( 1 0 0 )}$ \\
\hline
\end{tabular}

* The figure in brackets represent percentage origin :( Field Survey, 2019)

Form 4.1.2 Block of the responder

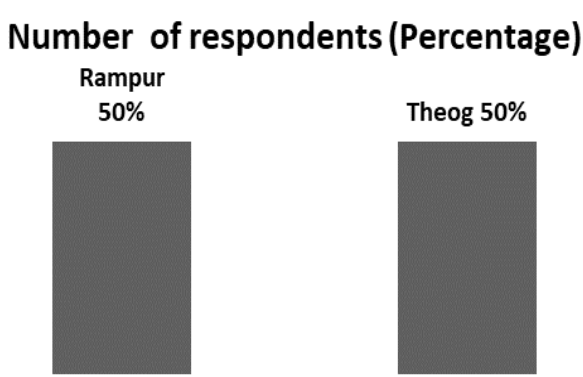

From the above tabulation, it is revealed that $50 \%$ of the respondents were from Rampur and $50 \%$ of the respondents were from Theog.

\subsubsection{Government Schemes used by Self Help groups}

\section{Goverment Schemes}

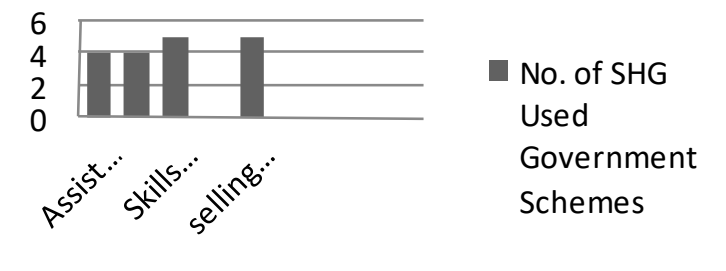

.2.5 Response based on Awareness of SHG Schemes Provided by Government Agencies to Promote Art \& Handicraft

Effectiveness Level of Marketing Services

\begin{tabular}{|l|c|c|c|c|c|}
\hline Parameters & $\begin{array}{c}\text { highl } \\
\text { Y(3) }\end{array}$ & $\begin{array}{c}\text { Mode } \\
\text { rate } \\
\text { (2) }\end{array}$ & $\begin{array}{c}\text { Le } \\
\text { ast } \\
\text { (1) }\end{array}$ & $\begin{array}{c}\text { Total } \\
\text { Weichthe } \\
\text { Score (TWS) }\end{array}$ & Rank \\
\hline $\begin{array}{l}\text { Assistance } \\
\text { to SHG }\end{array}$ & 6 & 4 & 0 & 26 & 2 \\
\hline $\begin{array}{l}\text { Cluster } \\
\text { Developm } \\
\text { ent }\end{array}$ & 4 & 6 & 0 & 24 & 3 \\
\hline $\begin{array}{l}\text { Skills } \\
\text { Training } \\
\text { on } \\
\text { Handicraft }\end{array}$ & 7 & 3 & 0 & 27 & 1 \\
\hline $\begin{array}{l}\text { Direct } \\
\text { Indirect } \\
\text { Marketing }\end{array}$ & 2 & 7 & 1 & 21 & 4 \\
\hline $\begin{array}{l}\text { Promoting } \\
\text { Schemes }\end{array}$ & 1 & 7 & 2 & 19 & 5 \\
\hline $\begin{array}{l}\text { Market } \\
\text { Expansion }\end{array}$ & 0 & 5 & 5 & 15 & 8.5 \\
\hline $\begin{array}{l}\text { Growth \& } \\
\text { Developm } \\
\text { ent }\end{array}$ & 1 & 5 & 4 & 17 & 6 \\
\hline $\begin{array}{l}\text { Sustainabil } \\
\text { ity }\end{array}$ & 0 & 6 & 4 & 16 & 7 \\
\hline Flexibility & 0 & 4 & 6 & 14 & 10 \\
\hline $\begin{array}{l}\text { Organizati } \\
\text { onal } \\
\text { Support }\end{array}$ & 0 & 5 & 5 & 15 & 8.5 \\
\hline
\end{tabular}

4.2.5 Response based on Awareness of SHG Schemes Provided by Government Agencies to Promote Art \& Handicraft

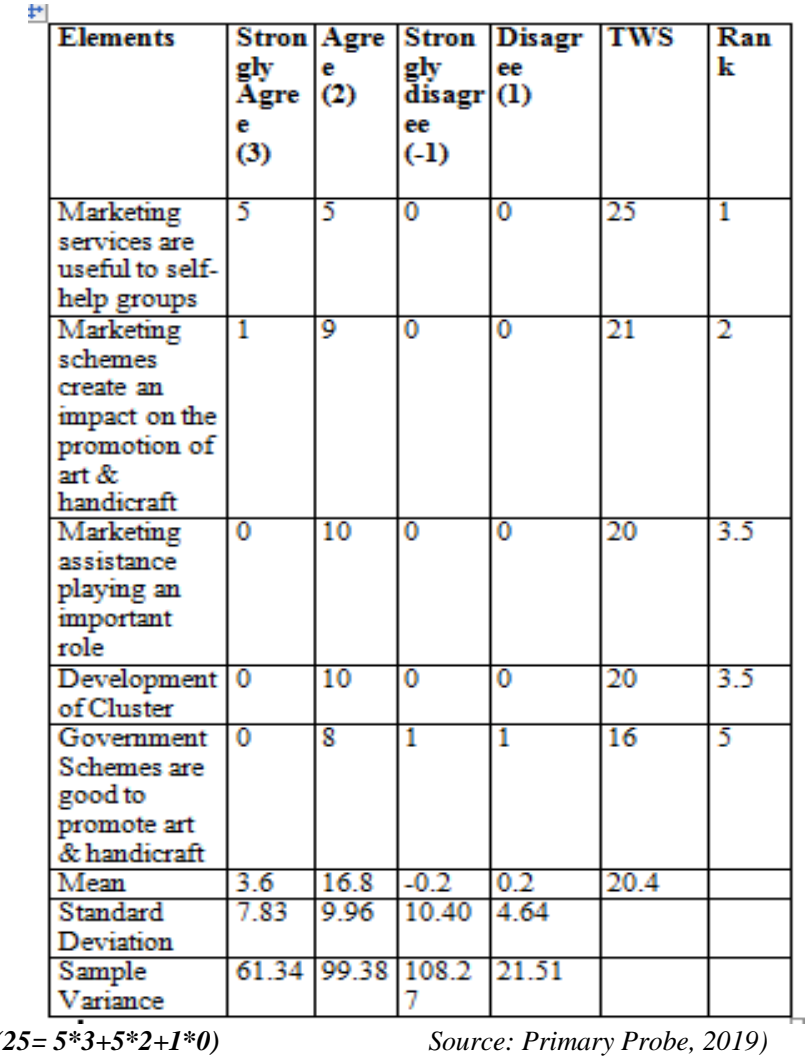

\section{SUMMARY AND CONCLUSIONS}

The present study was about "Marketing facilities provided by government agencies to promote art \& handicraft "with the following specific objectives:

To study the key Marketing Facilities provided by The Government agencies for the Promotion of Art \& Handicrafts.

To Study the awareness level of Self-Help Groups towards different Marketing Schemes promoted by H.P Government to Promote Handicraft.

To Study the Perception of Self Help Groups regarding various Marketing Schemes endorsed by Government in Himachal Pradesh.

The research was done with a random sample of 20 Groups. As far as the demography formation of the observed data, the paramount number of respondents was female respondents. While analysing the Organisation, which promoted the self-help Groups it was observed that Banks and Financial Institutions (50\%) are more actively involved in promotion activities. Where other organisations such as NGO, s Govt. Department, Cooperate Society and self (50\%) are involved SHG promotion

It has been observed from the data that maximum self-Help Groups (75\%) have economical Key objectives where (25\%) have occupational Objectives While analysing the preferential marketing facilities used by self-help group's it was observed that Maximum (100\%) Self-help groups using open exhibition and handicraft fairs rather than online shopping and marketing assistance.

Published By:

Blue Eyes Intelligence Engineering \& Sciences Publication (C) Copyright: All rights reserved.

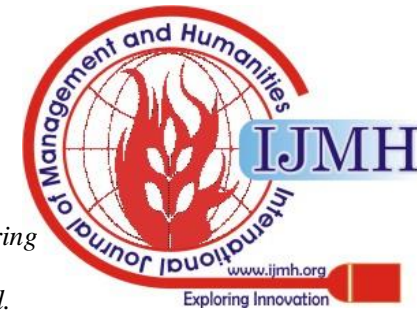


It was also revealed by the analysis that (60\%) SHG, s is aware of these schemes provided by government agencies to promote art and handicraft. Where (80\%) SHG has experienced marketing services.

While analysing the opinion of the self-help groups, it was found that they were largely Agree or somehow strongly agree with the marketing services, marketing assistance, development of cluster is playing important role in the promotion of art and handicraft. While observing the effectiveness level of marketing services provided by government agencies to promote art and handicraft it was observed that schemes are largely moderately affective and somehow highly effective.

\section{REFERENCES}

1. Government Agency Promoting Art \& handicraft, Handicrafts.nic.in/, (2015). http://www.ub.umu.se/

2. Kothari, C.R. (2009). Research methodology: methods and techniques. Second edition New Delhi: New Age International Publisher, pp. 314-390.

3. Hashmi, S. K. (2012). The market for Indian Handicrafts. Excel Journal of Engineering Technology and Management Science (ISSN 2249-9032), I (1), 6, 7.

4. Rao, R. (1979). Small Industries and the Developing Economy in India. New Delhi: Concept Publishing.

5. Barnard, Nicholas, Arts and Crafts of India. London: Conran Octopus Limited. (1993). p. 14

\section{AUTHOR PROFILE}

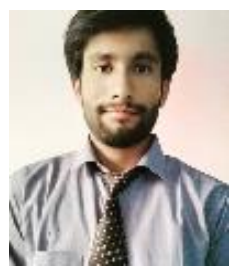

Devender Sharma, is working as Assistant Professor in Green Hills Engineering college Solan Himachal Pradesh. He has a keen Interest in Research in various fields like Human Resource management, Marketing, Economics and Retail. He has done MBA, MEC, PGDAS, He is Pursuing $\mathrm{PhD}$ in Developmental Psychology. He has also an interest in Poetry and literature. 